\title{
VALIDITY OF SOFTWARE FOR MEASUREMENT OF TOTAL REACTION TIME WITH SIMPLE STIMULUS -TRT_S 2012
}

\author{
Tânia Brusque Crocetta ${ }^{1,2}$, Ricardo Luís Viana2,3, Douglas Eric Silva ${ }^{2,3}$, \\ Carlos Bandeira de Mello Monteiro ${ }^{1,4}$, Claudia Arab ${ }^{1,2}$, Alexandro Andrade
}

DOI: dx.doi.org/10.7322/jhdg.88963

\begin{abstract}
Objective: Determine the validity of the TRT_S $\mathrm{S}_{2012}$ software in to assess the total reaction time (TRT) with a simple visual stimulus (TRTSimple) and mental fatigue from TRT (TRTFatigue). Methods: Three types of validation were applied: a) concurrent, for determining the correlation between the TRT_S ${ }_{2012}$ Software and Vienna Test System (VTS), b) content of a sample of adults, and c)mechanical, using a robot that performs a mechanic motion to respond to a light stimulus. The study included 216 young adults, college students aged $17-45$ years $(x=24.0 \pm 6.0)$ and a robot. Descriptive and inferential statistics were used for performance on TRT obtained by young adults and robot in two software. Results: The intra-class correlation in the adults TRT showed strong correlation between VTS and TRTSimple $(R=.72)$. Identification of the proposed initial stimulus in TRTFatigue presented intermediate correlation with VTS $(R=.56)$ and the final stimulus presented low correlation with VTS $(R=.35)$. The robot TRT showed standard deviation ranging $.5 \mathrm{~ms}$ (on average) between the highest and lowest. The standard error of the mean ranged from .23 to .28 and the distributions were homogeneous between 8.2 to $9.7 \%$. Conclusion: The results confirmed the validity of the software TRT_S ${ }_{2012}$. It is a reliable cognitive test that can be applied to young adults for measuring the TRT with simple visual stimuli and for evaluating the influence of mental fatigue from the TRT. however, the delays caused by the computer resources used should be considered and measured with a resource like the robot. We conclude that the TRT_S ${ }_{2012}$ software is valid for assessing the TRT and cognitive fatigue in healthy adults.
\end{abstract}

Key words: reaction time, mental fatigue, software.

\section{INTRODUCTION}

The diagnosis, treatment, and prevention of disease, illness, injury, and other physical and mental impairments in humans are conventionally regarded as health care and the term provider extends far beyond ${ }^{1}$ and the use of simple measures for health care and rehabilitation has a great value and interest to researchers.

The simple reaction time is a measure of how quickly a person performs a uniform response to a specific stimulus, and has clinical relevance in relation to function and health².

The registration of reaction time (RT) provides a more refined research on neuropsychological functioning than simple measurement of the number of correct and wrong answers, as it is a highly sensitive variable ${ }^{3}$.

The RT is probably the most widely used behavioral measure in units of time (usually in milliseconds), and has played an important role in research in psychology and related fields ${ }^{4}$. The main areas of application for studies of RT are clinical and health psychology, personnel psychology, sports psychology, and educational psychology ${ }^{5}$. Considering the importance of using tests with RT tasks, Crocetta et al. ${ }^{6}$ presented the software TRT_S ${ }_{2012}$ and proposed its use in any computer configuration, using the key board to record the response to the stimulus. Cronbach's alpha for the total reaction time test was $\alpha=0.84$ and evaluating the mental fatigue from the TRT presented internal consistency of $\alpha=0.62$ to identify the initial stimulus and $\alpha=0.87$ to identify the end of the stimulus.

Working on tasks that require great cognitive effort for a considerable time often leads to mental fatigue that can affect performance on task execution. It is important to prevent or treat the errors related to mental fatigue and understand their nature and specific effects on behavior?. The validation of this test in the TRT_S ${ }_{2012}$ software can benefit several areas of research.

Building a robot similar to that proposed by Neath et al. ${ }^{8}$, Crocetta et al. ${ }^{9}$ validated the measurements obtained by the robot called Emboici

\footnotetext{
1 Laboratório de Delineamento de Estudos e Escrita Científica, Departamento de Saúde da Coletividade, Faculdade de Medicina do $A B C$.

2 Laboratório de Psicologia do Esporte e do Exercício, Centro de Ciências da Saúde e do Esporte, Universidade do Estado de Santa Catarina.

3 Especialistas em programação Java.

4 Escola de Artes, Ciências e Humanidades da Universidade de São Paulo.

5 Programa de Pós-graduação Strictu Sensu em Ciências do Movimento Humano.

Corresponding author: tania.crocetta@udesc.br
}

Suggested citation: Crocetta TB, et al. Validity of software for measurement of total reaction time with simple stimulus - trt_s2012. 24(3): 295-303

Manuscript submitted Jun 05 2014, accepted for publication Oct 282014. 
Robot: $46.95 \mathrm{~ms}( \pm 6.04)$ at 1200 measures of TRT. The purpose of this robot was to react by pressing a button when a light stimulus was identified by a photodiode. The Emboici Robot can be used to assess the accuracy of measurement time in a test of TRT.

In this study it was assumed that the TRT involves identification of the stimulus, interpretation, and preparation of the response and effective motor action ${ }^{10,11}$. The validation process has not been exhausted; on the contrary, it assumes continuity and should be repeated several times for the same instrument ${ }^{12}$, and as with any new tool, it is important to directly compare the neuropsychological test results with existing tools that are already used to help understand the properties of the new tests and their comparability with conventional tests ${ }^{13}$.

Thus, the objective of this study was to validate the software TRT_S ${ }_{2012}$ to measure total reaction time to visual stimuli and to assess the influence of mental fatigue from the TRT.

\section{METHODS}

The research approved by the Ethics and Human Research Committee (Protocol n 63411/ 2012 and 102178).

\section{Participants}

Participants in the study comprised 216 young adult volunteers. They were university undergraduate and postgraduate students aged between 17 and $45(\bar{x}=24.0 \pm 6.0)$ including 99 men (45.8\%) with a mean age of 25.5 ( \pm 7.0 ) and 117 women $(54.2 \%)$ with a mean ageof $22.7( \pm 4.7)$. These volunteers were recruited by e-mail sent to students at a university campus in Florianopolis, SC, Brazil. All signed an Informed Consent.

A robot called Emboici Robot (Figure 1) also took part in the study with performance in TRT_S 2012 software and the Vienna Test System (VTS).

\section{Instruments}

Each participant completed the following tests: 1) Total Reaction Time (TRT) with simple visual stimulus (TRTSimple), 2) evaluation of the influence of mental fatigue from TRT (TRTFatigue) - these two tests are offered by TRT_S ${ }_{2012}$ - and 3) the Simple Reaction Time test with a yellow stimulus on the VTS.

TRT_S ${ }_{2012}$ Software. The software was developed and validated by Crocetta et al. ${ }^{6}$ in a sample of 76 healthy adults. The Software (Figure 1a) proposes the tests: TRTSimple and TRTFatigue.

The TRTSimple test consisted the appearance of a yellow square (configurable) in the center of the monitor predefined time intervals (ranging from 1.5 to $6.5 \mathrm{~ms}$ - these intervals were identical in both software) and when the stimulus, the participant should respond as quickly as possible by pressing the space bar on the computer keyboard.

The TRTFatigue test consisted in monitoring the bar in yellow color displacement, in a computer screen, from left to right, where the participant should respond as quickly as possible by pressing the space bar on the keyboard when the appearance of color (configurable) and keep the space bar pressing watching the displacement of the bar yellow stimulus until it disappeared, then when the space bar should be released. Two TRTs were identified: TRTiFatigue to press the space bar and TRTfFatigue upon release.

The software was parameterized with five executions for familiarization, 28 executions for TRTSimple (same number of executions proposed by VTS) and 14 executions for TRTFatigue.

Vienna Test System (VTS). The VTS is composed of a battery of psychometric tests (Figure 1b) where the TRT simple visual stimulus test (S9 Simple Reaction Yellow) presents reliability with Cronbach's alpha $=0.961^{14}$ and records the time of the reaction in milliseconds ( $\mathrm{ms}$ ). The participant should respond "as quickly and accurately as possible" to the visual stimulus (the appearance of

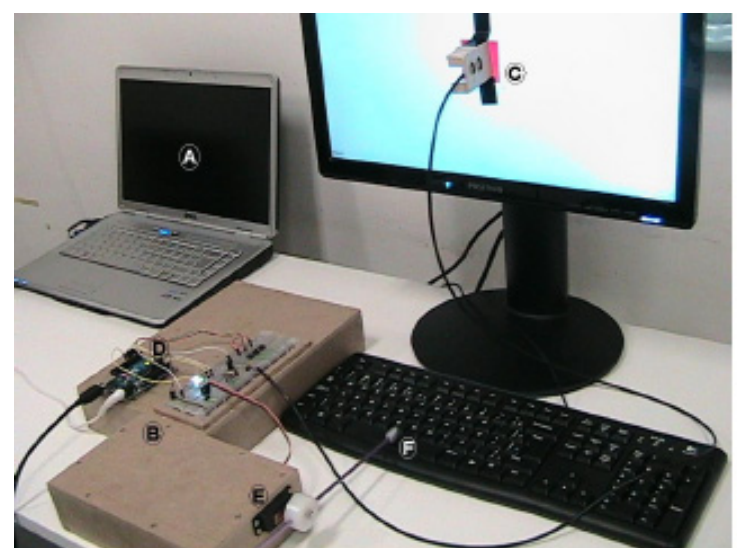

(a)

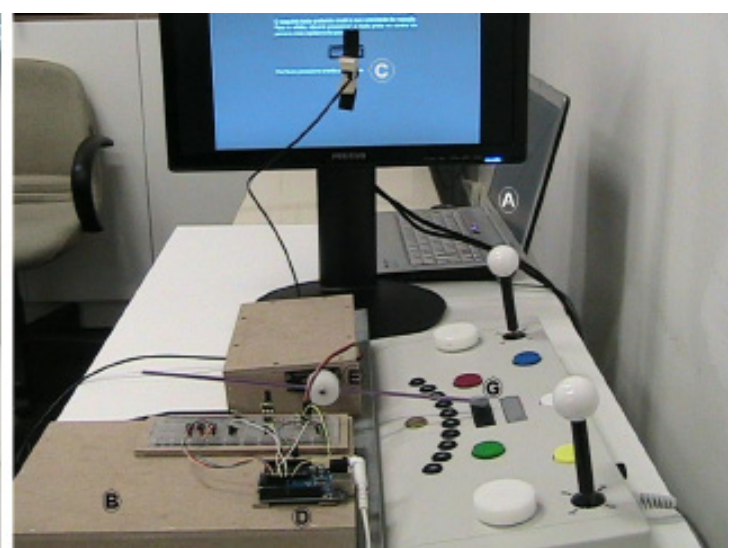

(b)

\section{Figure 1}

Pictures of the instruments and equipment used in this study.

(a)=Emboici Robot performing the total reaction time test on TRT_S 2012 software;

(b) =Emboici Robot performing the test of simple reaction time on the Vienna Test System (VTS) software.

$\mathrm{A}=$ Notebook; $\mathrm{B}=$ Emboici Robot, composed of a photodiode attached to the monitor; $\mathrm{C}=$ Monitor; $\mathrm{D}=\mathrm{Arduino}$ board;

$\mathrm{E}=$ digital servo motor pressing the keyboard or response panel; $\mathrm{F}=$ Keyboard; $\mathrm{G}=$ Response panel of the VTS. 
a yellow circle in the center of the monitor) by pressing a black button on the response panel that accompanies the VTS ${ }^{5}$. The VTS consists of five familiarization executions and 28 to compose the battery implementation of TRT (these numbers cannot be changed).

\section{Equipments}

Emboici Robot. Constructed and validated by Crocetta et al. ${ }^{9}$, this robot is composed of a photodiode that detects the change of brightness on the monitor (color stimulus generated by the software), triggering a digital servo motor that pushes a button (the space bar of the computer keyboard or the response panel button). This set is managed by an Arduino board (Figure 1-D). Crocetta et al. ${ }^{9}$ reported that the TRT obtained by Emboici Robot (time elapsed between the identification of the stimulus and the pressing of a button) was $46.95 \mathrm{~ms}$ ( \pm 6.04) after analysis of 1,200 measures. This runtime of Emboici Robot was the benchmark for comparison with the time recorded on the software TRT_S 2012 and VTS.

The TRT_S ${ }_{2012}$ software was parameterized to generate 99 executions for the TRTSimple test, which consisted of completing a square in the center of the monitor with red color on Day 1 and with a yellow color on Day 2 and Day 3. These executions were repeated 13 times on Day 1,11 times on Day 2, and 12 times on Day 3, generating 1287,1089 , and 1188 measurements for each day, respectively. The VTS did not allow the number of executions in each test (28) to be changed, so the test was repeated 27 times, resulting in 756 measures. The measurements were recorded by the software TRT_S ${ }_{2012}$ and VTS and exported to IBM $^{\circledR}$ SPSS $^{\circledR}$ 20.0. statistical software for analysis as described below.

Computer. All tests were performed on a Dell notebook computer with an Intel ${ }^{\circledR}$ Core 2 Duo T5800 $2.00 \mathrm{GHz}$ (external clock of $200 \mathrm{MHz}$ ) with $2 \mathrm{~Gb}$ of RAM and Enterprise Windows 7 Professional 32-bit, Service Pack 1 operating system. The equipment was formatted and Windows was installed from CD in the basic way without any additional configuration or upgrade, to reduce the influence of other software running on the operating system.

The Java virtual machine (JVM) required for the implementation of TRT_S $\mathrm{S}_{2012}$ software was version 7, update 21 (build 1.7.0_21-b11).

The stimuli were generated on a 19 -inch LCD monitor with a resolution of $1440 \times 900$ pixels and a refresh rate of $60 \mathrm{~Hz}$ (Mobile Intel Graphics Adapter 965 Express Chipset Family $384 \mathrm{Mb}$ ). An Intel graphic chipset GL960/GM965 Graphics Controller 0 (GPU speed of $500 \mathrm{MHz}$ ) was used. The pixel fill rate of 4000 Mpixels/s describes how many pixels the card can process in a second, which determines how fast the image can be composed ${ }^{15}$. The monitor was connected to the VGA output of the laptop and the projection was activated only on this display.

The response to the stimulus was generated by a Logitech USB Keyboard K120 (delay:1; repetition frequency: 31 ) when the test was applied using the TRT_S ${ }_{2012}$ software and by the response panel when applied using VTS.

\section{Procedures}

Procedures for collecting the TRT with young adults. All tests were performed in a room reserved for the presence of only the participant and a researcher and applied in a single session. The sequence of execution tests was varied among the participants, and the sequence for each participant was annotated with the abbreviations $T$ for TRTSimple, F for TRTFatigue, and V for VTS; therefore, the sequences were TFV, FTV, VTF, or VFT.

Procedures for collection of the TRT with

Emboici Robot. All tests were performed in a reserved area and all executions of Emboici Robot were videotaped. On Day 1, the TRT was collected using first TRT_S 2012 and then VTS. On Day 2 and Day 3 , the TRT was collected using only TRT_S ${ }_{2012}$. The photodiode was attached to the computer monitor with tape at the position where the change of the stimulus occurred (yellow circle for VTS and red/yellow square for TRT_S ${ }_{2012}$ ) (Figure $1 \mathrm{a}-\mathrm{C}$ and Figure $1 b-C)$.

The Emboici Robot was positioned in the middle of the keyboard space bar for collection in TRT_S ${ }_{2012}$ and in the middle of the black key response panel in VTS to the facilitate press (Figure $1 \mathrm{a}-\mathrm{F}$ and Figure $1 \mathrm{~b}-\mathrm{G})$. After color calibration and positioning of the press, the Emboici Robot made a movement back of three degrees and waited for the change of the stimulus. When the parameterized color was show on the monitor, the arm made a movement of three degrees, causing the button to be pressed. The time between the sending of the stimulus and the pressing of the space bar or button was stored by the respective software and composed the TRT measures. Measurements were performed with TRT_S ${ }_{2012}$ on three different days, providing 1287, 1089, and 1188 measurements, making a total of 3,564 , while 756 executions were performed with the VTS in just one day.

\section{Data processing}

TRT of young adults. Scores of the same participant in the VTS and TRT_ S $_{2012}$ software were compared for concurrent validity.

Measures of TRT (milliseconds) and accuracy (percentage of responses which were correct) were generated for each test.

Performance values for TRT above $1,000 \mathrm{~ms}$ were considered extreme and those below $100 \mathrm{~ms}$ were considered anticipations. Both were excluded from the analyses and accounted for $0.2 \%$ of the total of 18,144 measures of TRT; where as a method of filtering and elimination of outliers is considered very conservative if it rejects less than $5 \%$ of cases $^{4,16}$. The TRT measures were examined to identify normality. The TRT performances for all the tests were normally distributed and the coefficient of intra-class correlation (ICC) was calculated using the IBM $^{\circledR}{ }^{\circledR}$ program SPSS ${ }^{\circledR}$ version 20.0 .

The TRT measures and precision were calculated for each individual test. These values were then transformed into a common metric by calculating a individual in all the tests using the equation:

( $\left.\frac{\text { Individual Performance-Average Performance Group }}{\text { Average Standard Desviation }}\right)$ 
The precision measurements of all tests are presented as percentages and are not normally distributed. To make these data regular, arcsinesquare transformation was performed.

The ICC was calculated between the TRTSimple and VTS and between each measure of TRTFatigue and the VTS. ICC values near to 1 were interpreted as indicating greater agreement between the measurements of TRT_S 2012 and VTS.

Descriptive statistics (means, standard deviations, and minimum and maximum values) and $95 \%$ confidence intervals were calculated for the measurements of TRT and precision. Cronbach's alpha was also calculated for the TRT.

TRT Treatment of robot Emboici Robot. The mechanical and functional validity was assessed through descriptive analysis of TRT obtained by the robot in both software. 756 measures TRT were used with VTS and 3,564 with TRT_S ${ }_{2012}$ totaling 4,320 TRT measures. Three measures of TRT were invalidated in the VTS (were not recorded by the software), representing $0.4 \%$ of 756 measurements.

\section{RESULTS}

Descriptive statistics on the performance of young adults TRT tests proposed by software TRT_S 2012 and Vienna Test System (VTS) are described in Table 1.

The mean TRT were faster in tests with simple visual stimuli (TRTSimple and TRTVienna)

Table 1: Average data of performance measures in total reaction time (TRT) obtained by 216 young adults in Software TRT_S 2012 and Vienna Test System

\begin{tabular}{|c|c|c|c|c|c|}
\hline & $\operatorname{Mean}(S D)$ & Min & Max & CI $95 \%$ & $\alpha$ \\
\hline \multicolumn{6}{|l|}{ TRTSimple } \\
\hline Performance (ms) & $286.5(30.0)$ & 227.6 & 452.9 & $282.5-290.6$ & 0.93 \\
\hline Accuracy $(\%)$ & $98.7(2.4)$ & 85.7 & 100.0 & 98.3-99.0 & - \\
\hline \multicolumn{6}{|l|}{ TRTiFatigue } \\
\hline Performance (ms) & $367.5(34.8)$ & 299.4 & 479.3 & $362.8-372.1$ & 0.83 \\
\hline Accuracy $(\%)$ & $93.0(8.1)$ & 64.3 & 100.0 & 91.9-94.0 & - \\
\hline \multicolumn{6}{|l|}{ TRTfFatigue } \\
\hline Performance (ms) & $385.5(38.6)$ & 291.8 & 531.0 & $380.3-390.7$ & 0.74 \\
\hline Accuracy (\%) & $96.1(11.8)$ & 42.9 & 100.0 & 84.5-87.7 & - \\
\hline \multicolumn{6}{|l|}{ TRTVienna } \\
\hline Performance (ms) & $237.5(28.0)$ & 177.1 & 350.5 & $233.7-241.2$ & 0.94 \\
\hline Accuracy (\%) & $99.8(1.3)$ & 85.7 & 100.0 & 99.7-100.0 & - \\
\hline
\end{tabular}

$S D=$ Standard deviation; Min = Minimum; Max = Maximum; CI = Confidence interval; $\alpha=$ Cronbach Alpha; TRTSimple = Total Reaction Time (TRT) with simple visual stimulus; ms = Milisseconds; TRTiFatigue = Identification of the proposed initial stimulus presented in TRTFatigue; TRTfFatigue = Identification of the proposed final stimulus presented in TRTFatigue; TRTVienna = Reaction Time in Vienna Test System software.

and slower in the evaluation of the influence of mental fatigue from TRT (TRTiFatigue and TRTfFatigue). Young adults showed perform better in the test proposed by the VTS. The Cronbach alpha for TRT above 0.74 indicate the reliability of the measurements obtained.

Performance on TRTSimple showed high positive correlation with TRTVienna $(R=0.72)$.
The performance TRTiFatigue showed intermediate correlation $(R=0.56)$ and performance in TRTfFatigue low correlation with TRTVienna $(R=0.35)$. Performance accuracy of the Software TRT_S 2012 not correlated with the VTS (Table 2).

The performance with Emboici Robot in the TRT simple visual test in TRT_S ${ }_{2012}$ software and

Table 2: Intra-class correlation (ICC) and confidence intervals (CI) between the Software measures TRT_S 2012 and Vienna Test System

\begin{tabular}{|c|c|c|c|c|c|c|c|c|c|}
\hline \multicolumn{10}{|c|}{ Software TRT_S ${ }_{2012}$ measures } \\
\hline \multirow{3}{*}{ TRTVienna } & \multicolumn{3}{|c|}{ TRTSimple } & \multicolumn{3}{|c|}{ TRTiFatigue } & \multicolumn{3}{|c|}{ TRTfFatigue } \\
\hline & \multicolumn{3}{|c|}{$95 \% \mathrm{CI}$} & \multicolumn{3}{|c|}{$95 \% \quad C I$} & \multicolumn{3}{|c|}{$95 \% \mathrm{CI}$} \\
\hline & ICC & Inf. & Sup. & ICC & Inf. & Sup. & ICC & Inf & Sup. \\
\hline Performance (ms) & 0.72 & 0.65 & 0.78 & 0.56 & 0.46 & 0.65 & 0.35 & 0.22 & 0.46 \\
\hline Accuracy (\%) & -0.005 & -0.14 & 0.13 & -0.032 & -0.16 & 0.10 & 0.000 & -0.13 & 0.13 \\
\hline
\end{tabular}

Note: The intra-class correlations are values between 0 and 1 , where higher value indicates a higher correlation between tests.

VTS with the descriptive statistics are shown in Table 3.

There was big difference in performance with the Emboici Robot in TRT_S ${ }_{2012}$ and VTS software compared with their performance (running average of $46.95 \mathrm{~ms}$ at $1,200(S D=6.04)$ measures TRT) reported by Crocetta et al ${ }^{9}$. Furthermore, the TRT recorded at TRT_S ${ }_{2012}$ Software was higher than the 
Table 3: Measures of central tendency, range and standard deviation for total reaction time (in milliseconds) measured at two kinds of software (TRT_S ${ }_{2012}$ and Vienna Test System) obtained by the robot Emboici Robot.

$\begin{array}{lcc} & \text { Software: } & \text { Vienna Test } \\ \text { System }\end{array}$

VTS only when the stimulus color was yellow. The standard deviations in all measures were very similar ranging 0.5 between higher and lower. The standard error of average ranged from 0.23 to 0.28 indicating good precision for all measurements. The distributions were homogeneous between 8.2 to $9.7 \%$.

To check whether there were differences between TRT measured by two software the Mann-
Whitney test was applied where differences were observed statistically significant between VTS and TRT_S ${ }_{2012}$ software with $p=0.000$ for the stimulus red $(Z=-7.54)$ or yellow $(Z=-23.42$ and $Z=-24.33$ for day 2 and Day 3 , respectively). The same occurred when applying the Kolmogorov-Smirnov test for TRT_S ${ }_{2012}$ Software and VTS (Table 4). These same tests were applied

Table 4: Application of the Mann-Whitney and Kolmorov-Smirnov test for measurements with robot Emboici Robot with TRT_S ${ }_{2012}$ and Vienna Test System software in three distinct days (with color change of stimulus for Software TRT_S 2012 )

\begin{tabular}{|c|c|c|c|c|}
\hline \multicolumn{5}{|c|}{ Software TRT_S 2012} \\
\hline Stimulus color: & & Red & Yellow & Yellow \\
\hline Day of measurement: & & Day 1 & Day 2 & Day 3 \\
\hline Vienna Test & MW & $Z=-7.54 *$ & $Z=-23.42 *$ & $Z=-24.33^{*}$ \\
\hline System & KS & $Z=3.40 *$ & $Z=9.99 *$ & $Z=10.32 *$ \\
\hline TRT_S 2012 & MW & & $Z=-31.38 *$ & $Z=-32.54 *$ \\
\hline Red Day 1 & KS & & $Z=13.78^{*}$ & $Z=14.12 *$ \\
\hline TRT_S ${ }_{2012}$ & MW & & & $Z=-0.90, p=0.366$ \\
\hline Yellow - Day 2 & KS & & & $Z=0.58, p=0.896$ \\
\hline
\end{tabular}

$*=p=0.000 ; \mathrm{MW}=$ Mann-Whitney $; \mathrm{KS}=$ Kolmorov-Smirnov.

to verify whether these differences are also observed in measures of TRT considering only TRT_S 2012 software on three different days where it was observed that the TRT distribution is the same when the test is only applied with the same color yellow stimulus (day 2 and Day 3 ).

Where as the mean, median and mode were approximately equal and showed that the asymmetry value between -1 and 1 , it can be assumed that the distribution was very close to normal ${ }^{17}$ and considering also the robustness of the statistical tests that ignore the possible non-normality of the TRT, were parametric tests shown in Table 5.

Comparing the results of the evaluations presented in Table 5, it rejects it null hypothesis of equality between the measurements of both software, the performance Emboici robot in Software TRT_S ${ }_{2012}$ showed significantly different times when compared to the VTS, being lower when the color was red stimulus and greater when the stimulus color was yellow (same color between the software). The TRT average in the evaluation with the red stimulus TRT_S ${ }_{2012}$ was $83.7 \mathrm{~ms}$ and in the VTS average was $86.5 \mathrm{~ms}$.

Also, rejects the null hypothesis of equality of measures of Emboici Robot performance in TRT_S ${ }_{2012}$ Software when the color stimulus was different (yellow and red), but accept the null hypothesis of equality when the colors were equal (yellow). The TRT average in red color was $83.7 \mathrm{~ms}$ and in yellow color were $97.0 \mathrm{~ms}$ and $97.3 \mathrm{~ms}$ for day 2 and Day 3, respectively. 
Table 5: Application of the t test for paired samples for measurements obtained with the software TRT_S 2012 Vienna Test System and the implementation of robot Emboici Robot in three days distinct (with color change of stimulus for Software TRT_S ${ }_{2012}$ )

$\begin{array}{lccc}\text { Couple with software, color stimulus and enforcement day } & \boldsymbol{t} & \boldsymbol{d f} & \boldsymbol{p} \\ \text { TRT_S }{ }_{2012} \text { red Day } 1 \text { and VTS } & -6.859 & 747 & 0.000 \\ \text { TRT_S }{ }_{2012} \text { yellow Day } 2 \text { and VTS } & 26.705 & 749 & 0.000 \\ \text { TRT_S } 2012 \text { yellow Day 3 and VTS } & 26.907 & 751 & 0.000 \\ \text { TRT_S }{ }_{2012} \text { red Day1 and TRT_S }{ }_{2012} \text { yellow Day 2 } & -38.653 & 1079 & 0.000 \\ \text { TRT_S }{ }_{2012} \text { red Day1 and TRT_S }{ }_{2012} \text { yellow Day 3 } & -39.721 & 1180 & 0.000 \\ \text { TRT_S }{ }_{2012} \text { yellow Day 2 and TRT_S }{ }_{2012} \text { yellow Day 3 } & -0.970 & 1082 & 0.332\end{array}$

$\alpha=0.05 ;$ VTS $=$ Vienna Test System; $d f=$ degrees of freedom.

\section{DISCUSSION}

This study aimed to validate the Software TRT_S ${ }_{2012}$ to measure the simple reaction time with visual stimuli, searching the concurrent validity between TRT_S 2012 and Vienna Test System (VTS) software, content validity by TRT young adults, and the mechanical and functional validity by Emboici Robot performance compared to the VTS and TRT_S 2012 software.

Little is known about the reliability of computerized tests to evaluate mental fatigue from the TRT because it was not found any software with a similar proposal. The results of this study seem to indicate that the test proposed by Software TRT_S ${ }_{2012}$ is reliable when administered to young adults.

This makes the software indicated for TRT_S ${ }_{2012}$ tests of mental fatigue, especially in activities where there is a risk of damage caused by fatigue. The results also suggest that in young adults, the performance measures in total reaction time (TRT) are more reliable than measures of accuracy response. This may have occurred because the accuracy of the participants' performance was near perfect in both tests as proposed by the Software TRT_S ${ }_{2012}$ and Vienna Test System.

Several authors have developed software with tests of single or choice reaction time (RT) presenting their validation ${ }^{18,19}$. The importance of testing with RT stimulate some authors to propose in struments more affordable for clinical application, validating with other software ${ }^{20}$ or a RT Electronic Tester $^{21}$.

In young adults the performances in TRT with simple visual stimuli were highly correlated, where as with the evaluation test of mental fatigue correlation was intermediate to the initial stimulus and very little with the final stimulus. One explanation for this is that the test of simple visual stimulus with TRT in both software evaluates the same cognitive processes, while similarity in the implementation of the evaluation of mental fatigue test from TRT occurs exactly with the identification of the initial stimulus when to press the button space. As for the identification of the final stimulus, the key must be released. These results may also suggest that the measures obtained in the evaluation test mental fatigue are more sensitive to the effects of mental fatigue than tests conventional. Other comparative studies on the clinical utility of the test fatigue evaluation may help clarify these differences.

Another analysis which may be performed on the difference in reaction time TRTSimple between the test and the differences relate TRTFatigue scale stimulus presentation between the two measurement methods. The appearance of color change to TRTFatigue is performed on a gradual scale. This results in a small visual angle. Especially in identifying the stimulus end. This test makes the correct identification of stimuli is much more difficult than the TRTSimple test.

Al though estimates of reliability of the intraclass correlation coefficient ICC $>0.90$ was ideal, this seems to be an unrealistic point of reference for a test evaluation of something as complex as the processing speed of the brain for prolonged periods of time ${ }^{20}$ as proposed in the assessment of mental fatigue test from TRT.

Reliability was considered appropriate because the lowest Cronbach's alpha was above 0.74 . Maroco and Garcia-Marques ${ }^{22}$ claim that the more high are the covariances (or correlations between items, represented by alpha Cronbach), the greater the homogeneity of the items and with greater consistency than measure the same dimension or the teoretical construct. So, as these coefficients approached $1(0.93,0.83$ and 0.74 respectively for TRTSimple, TRTiFatigue and TRTfFatigue), meaning that more consistent and therefore more reliable the instrument. The Cronbach's alpha for the VTS coefficient of 0.94 confirms by Schuhfried and Prieler ${ }^{14}$.

The average data in Table 1 indicate that young adults respond quickly and generate few errors in tests of psychomotor function. However, they respond more slowly and generate more errors in the evaluation mental fatigue test. This effect is further exacerbated when in a learning test more complex ${ }^{13}$. Thus, the onset of mental fatigue can be studied by analyzing the progressive change in the processing efficiency information as a result of sustained mental activities ${ }^{23}$.

In the study of Schellekens et al. ${ }^{24}$, to investigate the hypothesis that longmental demands of work are reflected negatively on the implementation of attention tasks, only the number of errors was significantly higher at the end of the task more difficult. In the present study, the lowest accuracy 
was appointed to the identification of the final evaluation of mental fatigue test.

The same effect was observed for Lorist et al. ${ }^{25}$, to examine the mental fatigue effects in specific cognitive processes involved in the control planning and preparation of future activities, where with increasing mental fatigue, processes for the preparation seemed less adequate, and the number of errors increased.

1

In Table 5 we observe significant differences in the same TRT "day 1 " with changes only the color of the stimulus from yellow to red.Were homogeneous TRTs around the mean, in both the TRT in yellow as red color. The significant difference is precisely the fact that small differences in measurement are important when data vary only by changing the mounting the color on the monitor, but this could only be identified because the TRT were resulting behavior of the robot.

Ohyanagi and Sengoku ${ }^{26}$ presented a solution to measure the accuracy in reaction time, the SMART, and can be used on any computer that has a USB port. The authors conclude that SMART is a simple and practical solution to TRT measure, especially in clinical applications due to its stability, accuracy, size, cost and ease of use.

A very similar solution like Emboici Robot was proposed by Neath et al. ${ }^{8}$, where a photodetector identifies the screen changes in luminance, and when this occurs, a relay is activated which, in turn, activated a solenoid, which positioned on thekeyboard, pressed a key. The authors conclude that the TRT collected can detect as little as $5-10 \mathrm{~ms}$ difference, and this determines what types of research should or should not use certain systems.

More important to consider is the difference of more than $13 \mathrm{~ms}$ (on average) found when using the same software TRT_ $\mathrm{S}_{2012}$ just changing the color of stimulus (red to yellow). Despite the advantages of continuous lighting and low electromagnetic emission of a LCD (liquid crystal display), these monitors have problems with time and accurate presentation of color, milliseconds apart (sometimes even $10 \mathrm{~ms})^{27}$. Where as the refresh rate determines the speed at which an image is displayed on an LCD monitor, and usually starts at $60 \mathrm{~Hz}$ in modern monitors, that means it can take up to $16.6 \mathrm{~ms}$ for certain color appears in an LCD monitor coupledwith the fact that the update time of a pixel for an new pixel is usually $5 \mathrm{~ms}^{28}$. This makes us look with concern for the difference shown in the colorchange of the stimulus, suggesting that new tests can be conducted to determine differences in parameterization of other colors, as well as other types of monitors, keyboards and operational systems.

There is a difference between the reaction times measured with the computer, as verified with the use of the robot in two different software and this difference should be considered when designing paradigms study of leveraging technology current computers.

Reinforces the need to carefully evaluate the computational resources used (operating system, software programming, computer, keyboard and monitor), particularly when necessary to compare with diverse populations or with different stimuli such as the color, for example, taking care to evaluate the impact of each featureand using a reliable measuring equipment as robot Emboici Robot can help to identify possible differences in resources employed.

The Emboici Robot may vary, allowing the use of different components for use in different research and to meet different needs. It is possible replace the photosensor, the Arduino board, the digital servo motor and the rod itself pressing. A digital servo motor with higher power can give more speed to the arm movement and more strength at the timeof press, but these changes require new validation measures.

As for the tests proposed by Software TRT_S ${ }_{2012}$ can affirm that the sustained mental effort can negatively affect the well-being and health by activating physiological systems linked to stress reactions. Therefore, the clear identification of mental fatigue from the TRT can be a useful tool for several studies. Therefore, the TRT_S ${ }_{2012}$ Software is ideal for use in investigations on mental fatigue, in addition to simple TRT tests commonly used to monitor the recovery or to determine the severity of cognitive impairment or mental fatigue.

Our results confirm the feasibility of using time measurement reaction with useof computer and keyboard for neurocognitive assessment. Measurements are reliableand valid and current computer technology does not increase significantly the measurement error.

It is worth noting that the comparison of the performances obtained in different configurations of software and hardware must be accompanied by verification of delays caused by this set, and that this is only possible by use of a device developed specifically for this purpose with the robot Emboici Robot.

\section{CONCLUSION}

Taken together, the results of this study indicate that TRT_S ${ }_{2012}$ software is reliable and valid test when given to young adults. Moreover, the performances obtained in the TRT_S 2012 software correlates highly with the proposed Vienna Test System (VTS) test, which confirms that can use the computer keyboard with the same reliability of an accessory as the outer response panel of the VTS.

\section{Acknowledgments} Catarina.
UNIEDU Post graduate Program, Santa 


\section{REFERENCES}

1. Atrash $\mathrm{K}$, Carpentier $\mathrm{R}$. The evolving role of public health in the delivery of health care. Revista brasileira de crescimento e desenvolvimento humano. 2012;22:396-399.

2. Eckner JT, Richardson JK, Kim H, Lipps DB, Ashton-Miller JA. A Novel Clinical Test of Recognition Reaction Time in Healthy Adults. Psychological Assessment. Mar 2012; 24(1): 249-254.

3. Charchat $H$, Nitrini R, Caramelli $P$, Sameshima K. Investigação de Marcadores Clínicos dos Estágios Iniciais da Doença de Alzheimer com Testes Neuropsicológicos Computadorizados. Psicologia: Reflexão e Crítica. 2001;14: 305-316.

4. Baayen RH. Analyzing Reaction Times. International Journal of Psychological Research. 2010;3(2):12-28.

5. Vogt T, Schneider S, Abeln V, Anneken V, Struder HK. Exercise, mood and cognitive performance in intellectual disability-A neurophysiological approach. Behavioural Brain Research. Jan 2012;226(2):473-480.

6. Crocetta $T B$, Viana RL, Silva DE, Andrade A. Validação preliminar do Software TRT_S2012 para medição do Tempo de Reação Total: Estudo piloto [Preliminar validation of TRT_S2012 Software for measuring Total Reaction Time: A Pilot Study]; 2013 (Submitted):11.

7. Van der Linden D, Frese M, Meijman TF. Mental fatigue and the control of cognitive processes: effects on perseveration and planning. Acta Psychologica. 2003;113(1):45-65.

8. Neath I, Earle A, Hallett D, Surprenant AM. Response time accuracy in Apple Macintosh computers. Behavior Research Methods. Jun 2011;43(2):353-362.

9. Crocetta TB, Kroich T, Thiesen AC, Borges L, Borges Junior NG, Abreu LCd, et al. A Robot for Verifying the Precision of Total Reaction Time Measurement; Motriz. 2014 (ahead of print): 16 .

10. Zwierko T, Osinski W, Lubinski W, Czepita D, Florkiewicz B. Speed of Visual Sensorimotor Processes and Conductivity of Visual Pathway in Volleyball Players. Journal of Human Kinetics. Mar 2010;23:21-27.

11. Ishihara M, Imanaka K, Mori S. Lateralized effects of target location on reaction times when preparing for manual aiming at a visual target. Human Movement Science. 2002;21(5-6): 563-582.

12. Raymundo VP. Construção e validação de instrumentos: um desafio para a psicolinguística. Letras de Hoje. 2009;44(3):86-93.

13. Collie A, Maruff $P$, Makdissi M, McCrory $P$, McStephen M, Darby D. CogSport: Reliability cognitive tests used in and correlation with conventional postconcussion medical evaluations. Clinical Journal of Sport Medicine. Jan 2003;13(1):28-32.

14. Schuhfried G, Prieler J. Manual Vienna Test System - Teste de Reacções Simples e de Escolha [Vienna Test System Manual - Reaction Time]. In: $29.00 \mathrm{~V}$, ed. Mödling: Dr. G. Schuhfried Ges.m.b.H.; 2005:44.
15. Amoroso D. Como funcionam e como escolher uma placa de vídeo para você. http:// w w w . tecmundo. com . br/artigos imprimir.asp?c=1632. Accessed 27 jun.2013, 2013.

16. Lachaud CM, Renaud O. A tutorial for analyzing human reaction times: How to filter data, manage missing values, and choose a statistical model. Applied Psycholinguistics. Apr 2011;32(2):389-416.

17. Leech NL, Barrett KC, Morgan GA. SPSS for Intermediate Statistics: Use and Interpretation. 2. ed. ed. Mahwah, New Jersey, London: Lawrence Erlbaum Associates, Publishers; 2005.

18. Deary IJ, Liewald D, Nissan J. A free, easy-touse, computer-based simple and four-choice reaction time programme: The Deary-Liewald reaction time task. Behavior Research Methods. Mar 2011;43(1):258-268.

19. Spruyt A, Clarysse J, Vansteenwegen D, Baeyens F, Hermans D. Affect 4.0 A Free Software Package for Implementing Psychological and Psychophysiological Experiments. Experimental Psychology. $2010 ; 57(1): 36-45$

20. Eckner JT, Kutcher JS, Richardson JK. BetweenSeasons Test-Retest Reliability of Clinically Measured Reaction Time in National Collegiate Athletic Association Division I Athletes. Journal of Athletic Training. Jul-Aug 2011;46(4): 409-414.

21. Mercer VS, Hankins CC, Spinks AJ, Tedder DD. Reliability and Validity of a Clinical Test of Reaction Time in Older Adults. Journal of Geriatric Physical Therapy. 2009;32(3): 103-110.

22. Maroco J, Garcia-Marques T. Qual a fiabilidade do alfa de Cronbach? Questões antigas e soluções modernas? Laboratório de Psicologia. 2006;4(1):65-90.

23. Meijman TF. Mental fatigue and the efficiency of information processing in relation to work times. International Journal of Industrial Ergonomics. Jul 1997;20(1):31-38.

24. Schellekens JMH, Sijtsma GJ, Vegter E, Meijman TF. Immediate and delayed after-effects of long lasting mentally demanding work. Biological Psychology. May 2000;53(1):37-56.

25. Lorist MM, Klein M, Nieuwenhuis $S$, De Jong $R$, Mulder G, Meijman TF. Mental fatigue and task control: Planning and preparation. Psychophysiology. Sep 2000;37(5):614-625.

26. Ohyanagi T, Sengoku Y. A solution for measuring accurate reaction time to visual stimuli realized with a programmable microcontroller. Behavior Research Methods. Feb 2010;42(1).

27. Wang $P$, Nikolic D. An LCD monitor with sufficiently precise timing for research in vision. Frontiers in Human Neuroscience. Aug 2011;5.

28. Boyaci O, Forte A, Baset SA, Schulzrinne $H$, Ieee. vDelay: A Tool to Measure Capture-toDisplay Latency and Frame Rate. 2009 11th Ieee International Symposium on Multimedia (Ism 2009). 2009:194-200. 


\section{RESUMO}

Objetivo: Determinar a validade do software TRT_S ${ }_{2012}$ na avaliação do tempo de reação total (TRT) simples visual (TRTSimples) e na fadiga mental a partir do TRT (TRTFadiga). Métodos: Aplicou-se três validações: a) concorrente, para determinar a correlação entre os Softwares TRT_S ${ }_{2012}$ e Vienna Test System (VTS); b) de conteúdo, com uma amostra de adultos; e c) mecânica, usando um robô que executa um movimento mecânico respondendo a um estímulo luminoso. Participaram do estudo 216 adultos jovens, estudantes universitários com idades entre 17 e 45 anos $(x=24,0+6,0)$ e um robô. Utilizou-se estatística descritiva e inferencial para o desempenho no TRT obtido pelos adultos jovens e pelo robô nos dois softwares. Resultados: O coeficiente de correlação intraclasse do TRT dos adultos jovens apresentou forte correlação entre TRTSimples e o VTS $(R=0,72)$. Para o TRTFadiga, a correlação foi intermediária $(R=0,56)$ para identificação do estímulo inicial e baixa $(R=0,35)$ para o final, quando comparado ao VTS. Os tempos obtidos para o robô apresentaram desvio padrão semelhantes, variando 0,5ms (em média) entre o maior e o menor. O erro padrão da média variou de 0,23 a 0,28 indicando boa precisão para todas as medidas. As distribuições foram homogêneas variando de 8,2 a 9,7\%. Conclusão: Os resultados obtidos confirmaram a validade do Software TRT_S ${ }_{2012}$, sendo um teste cognitivo fidedigno, podendo ser aplicado em adultos jovens, para medição do TRT simples com estímulo visual e para avaliação da influência da fadiga mental a partir do TRT. Porém os atrasos causados pelo recurso computacional utilizado devem ser considerados e medidos com um recurso como o robô. Conclui-se que o software TRT_S ${ }_{2012}$ é valido para avaliar o TRT e a fadiga cognitiva em adultos saudáveis.

Palavras-chave: tempo de reação, fadiga mental, software. 